\title{
Understanding Identity Presentation in Medical Crowdfunding
}

\author{
Jennifer G. Kim ${ }^{1}$, Hwajung Hong ${ }^{2}$, Karrie Karahalios ${ }^{1,3}$ \\ ${ }^{1}$ University of Illinois at Urbana-Champaign, ${ }^{2}$ Ulsan National Institute of Science and Technology, \\ ${ }^{3}$ Adobe Research \\ jgkim2@illinois.edu, hwajung@unist.ac.kr,karrie@adobe.com
}

\begin{abstract}
People desire to present themselves favorably to others. However, medical crowdfunding beneficiaries are often expected to present their dire medical conditions and financial straits to solicit financial support. To investigate how beneficiaries convey their situation on medical crowdfunding pages and how contributors perceive the presented information, we interviewed both medical crowdfunding beneficiaries and contributors. While beneficiaries emphasized the serious of their medical situations to signal their deservedness of support, contributor participants gave less attention to that content. Rather, they focused on their impression of the beneficiary's character formed by various features of contributions such as the contributor's names, messages, and shared pictures. These contribution features further signaled common connections between the beneficiary and contributors and each contributor's unique involvement in the beneficiary's medical journey. However, the contribution amount resulted in judgement about other contributors. We suggest design opportunities and challenges that apply these results to the design of medical crowdfunding interfaces.
\end{abstract}

\section{Author Keywords}

Medical crowdfunding; identity; self-presentation.

\section{ACM Classification Keywords}

H.5.m. Information interfaces and presentation (e.g., HCI): Miscellaneous;

\section{INTRODUCTION}

People often share their medical difficulties online to seek emotional and informational support [30,37]. Recently, a growing number of people started to use online medical crowdfunding platforms to solicit financial support by leveraging extended social network [2,32]. Online medical

Permission to make digital or hard copies of all or part of this work for personal or classroom use is granted without fee provided that copies are not made or distributed for profit or commercial advantage and that copies bear this notice and the full citation on the first page. Copyrights for components of this work owned by others than the author(s) must be honored. Abstracting with credit is permitted. To copy otherwise, or republish, to post on servers or to redistribute to lists, requires prior specific permission and/or a fee. Request permissions from Permissions@acm.org.

CHI 2018, April 21-26, 2018, Montreal, QC, Canada

Copyright is held by the owner/author(s). Publication rights licensed to ACM.

ACM 978-1-4503-5620-6/18/04...\$15.00

https://doi.org/10.1145/3173574.3173708 crowdfunding campaigns allow the beneficiaries to receive not only monetary contributions but also non-monetary contributions including campaign promotions and offline contributions (e.g., food donations) [22,35]. Recent studies suggest that publicly presented information about medical crowdfunding beneficiaries on campaigns impacted the credibility of the beneficiary $[23,35]$ and the types of support contributors offer $[16,22]$. Thus, presenting the beneficiary's identity in an appropriate manner is critical to elicit a variety of support from contributors.

Researchers have investigated how people employ various strategies to present their identity favorably when sharing health difficulties online $[3,30]$. For example, some people only share the positive side of the difficulties they face [30], and some share concerns anonymously [3]. Other people only share their difficulties with a specific group of people (e.g., peer patients) who share similar experiences [30,37]. People sometimes decide not to share their challenges because of their desire to be portrayed as a strong person [30]. However, medical crowdfunding beneficiaries are expected to expose details of their dire situation in order to receive financial contributions. In this work, we investigate what strategies medical crowdfunding beneficiaries use to present their identity on crowdfunding campaigns and how their contributors perceive them.

The presentation of medical crowdfunding contributions can influence the impression of medical crowdfunding beneficiaries. Previous research found that a variety of contributions from many people signal the beneficiary's legitimacy [23,35]. For example, non-monetary contributions, which include online campaign promotions and offline contributions (e.g., babysitting), signaled that contributors invested their time and energy to help the beneficiary. Despite the benefits of collective non-monetary contributions, they are under-recognized on medical crowdfunding sites [22]. We need a better understanding of the impact of presenting both monetary and non-monetary contributions on medical crowdfunding campaigns.

In this work, we investigated 1) existing self-presentation practices and 2) the possibility of displaying a variety of contribution features on online medical crowdfunding campaigns by interviewing six beneficiaries and eight contributors who had participated in online medical crowdfunding campaigns. From the interviews, we found 
that beneficiary participants often struggle between presenting the positive and strong image that they prefer to show and the negative and impaired image that they perceived their contributors desire to see. However, rather than focusing on the medical hardships, our contributor participants were more interested in contribution features conveying the beneficiary's character and their common connections (e.g., mutual contributors) to the beneficiary.

These contribution features further had the unintended benefit of allowing beneficiary participants to tell a story about their medical journey and how they came to view themselves as a beloved member of a community. However, presenting contribution amounts resulted in judgmental attitudes by some contributors about other contributors. We suggest designing medical crowdfunding interfaces that go beyond presenting individual contribution amounts and move towards assisting storytelling for both beneficiaries and contributors. By providing a holistic view of the supportive community's interaction surrounding people with medical and financial problems, our design implications suggest better ways to design socio-technical systems for vulnerable individuals.

\section{ONLINE SELF-PRESENTATION}

Goffman states that individuals desire to convey a favorable image of themselves to audiences because they are inherently concerned with how other people perceive them [14]. People use cues such as facial expressions or clothing to convey a desirable self-image. When using online platforms, where most existing cues are invisible, users devise a completely different set of cues, such as profile photos or writing styles to convey certain impressions. Online medical crowdfunding platforms provide a set of interface features (e.g., a profile photo or a campaign description) that allow campaign creators to present the beneficiary's medical and financial situations. Using these features, beneficiaries select photos and write about their medical situations to signal the image or impression they want to convey. Potential contributors form an impression of the beneficiary based on these signals that may (or may not) motivate them to donate to the campaign. To better understand unique presentation opportunities in medical crowdfunding campaigns, this section explains how selfpresentation works in online crowdfunding platforms and online support groups.

\section{Presentation in Crowdfunding}

Crowdfunding is the practice of raising funds for a specific cause by leveraging an extended social network via the World Wide Web. Crowdfunding research has largely focused on entrepreneurial crowdfunding campaigns where fundraisers solicit donations in exchange for rewards in the form of products or services. Contributors of entrepreneurial crowdfunding campaigns often donate money to collect these rewards [12]. Thus, in entrepreneurial crowdfunding, cues signaling the fundraiser's expertise and reward quality are associated with the success of campaigns. Such cues include updates about the reward status [39], the fundraiser's success ratio in past campaigns [31], grammatical accuracy in the campaign description [29], and video quality [7].

In contrast to entrepreneurial crowdfunding, the purpose of medical crowdfunding is to raise funds for a beneficiary's medical expenses. Thus, potential contributors of medical crowdfunding do not expect high-quality materials because they understand that beneficiaries lack the time and energy to generate them due to their difficult medical situations [23]. Moreover, unlike entrepreneurial crowdfunding, medical crowdfunding beneficiaries may feel embarrassed about revealing the purpose of their fundraising: personal medical and financial difficulties. Although some people prefer to share their medical concerns anonymously [3] or emphasize the positive side of their difficulties [30], medical crowdfunding beneficiaries are expected to publicly disclose their real name and the seriousness of their medical situations. In this work, we investigate how beneficiaries present their situation on medical crowdfunding campaigns to convey why they deserve support and how contributors perceive the presented information.

\section{Presentation in Online Support Groups}

Individuals consciously decide how they share what information with whom, especially when sharing health information online [30]. For example, people often frame their health concerns positively on Facebook to be seen as a person who can cope with difficulties [40]. This desire to form a positive impression often prevents people from sharing health-related challenges on social media $[4,10]$. However, individuals are likely to share their health struggles more openly in online peer support groups [30]. Online peer-patients who are going through similar medical difficulties provide more empathetic emotional and informational support [20,37].

Recent online health-support research has investigated how people present their medical concerns to receive emotional and informational support [3,30,37]. However, less research has explored how people frame their medical situations to receive financial support. Requesting financial support introduces unique challenges because support seekers may feel embarrassed when soliciting money for their personal issues [22]. Despite this struggle, medical crowdfunding beneficiaries sometimes experience a positive shift in their identity through the medical crowdfunding process [16]. As they publicly present their health difficulties, they experience a form of therapy and become a person who can accept their identity as a patient. In other cases, beneficiaries come to view themselves as more "open, honest, and brave" rather than "sick" [16]. Inspired by this line of research, we aim to focus on how to present the beneficiary's situation to produce such positive changes in their identity. More specifically, we explore the following research questions: 
RQ1a: How do beneficiaries currently choose what information to highlight in their medical crowdfunding campaigns and why?

RQ1b: How do contributors perceive the information presented on medical crowdfunding campaigns?

\section{CONTRIBUTORS \& CONTRIBUTIONS}

Medical crowdfunding is not solely about monetary contributions $[16,22]$. Non-monetary contributions such as social media shares and offline contributions result in a large volume of financial donations and emotional support [22,35]. For example, beneficiaries often felt sense of security and assurance when seeing contributors promoting campaigns on their behalf and providing different types of support such as serving food or babysitting [15,22]. While beneficiaries acknowledge the value of non-monetary contributions, current medical crowdfunding interfaces mostly emphasize monetary contributions. Each monetary contributor's name, donation amount, message, and donation date are publicly displayed on the right side of a campaign (see Figure 1-3). However, non-monetary contributions are often presented as a total number of shares (see Figure 1-1).

Recently, GoFundMe started recognizing non-monetary contributions on its interface. One such contribution is the act of sharing a campaign online. By sharing a campaign online, one can compete to join the list of the top five contributors on their "Most raised from sharing" interface (see Figure 1-2). This is just one example of recognizing non-monetary contributors on a campaign interface. However, we still have a limited understanding of how beneficiaries and contributors prefer to display nonmonetary contributions and what inferences they make from the displayed contributions.

\section{Cues to Present Contributors \& Contributions}

To understand how medical crowdfunding beneficiaries and contributors desire to recognize contributors and contributions, we first explored how other online communities and social media sites recognize their contributors and contributions. A large body of research in Human Computer Interaction $[5,8,9,11,24,25,28,40]$ has investigated how people use visible online cues to signal and infer invisible qualities of contributors and contribution recipients (e.g., people's ability, popularity, or trustworthiness). While examining the research literature, we identified 1) the cues that are already used to display monetary contributions on current medical crowdfunding interfaces (e.g., contributor names) and 2) additional cues related to non-monetary contributions (e.g., links to where the campaign was shared online). In this section, we organize the cues that are relevant to displaying medical crowdfunding contributors and contributions, and refer to them as contribution features. The contribution features are defined as any visible information about medical crowdfunding contributions that signal invisible qualities possessed by the contributors or contribution recipients.

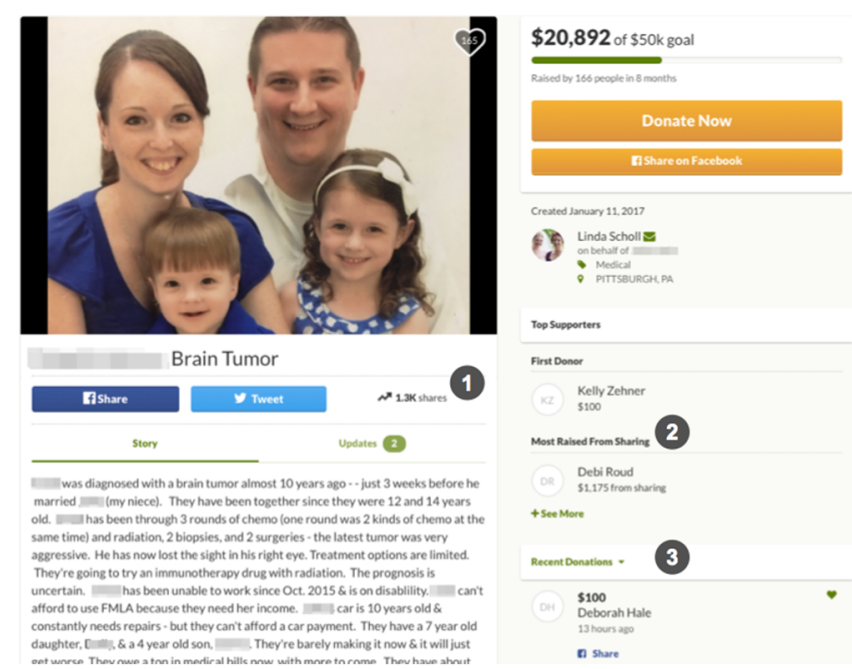

Figure 1. An example of GoFundMe medical crowdfunding campaign interface: Campaign creators can display photos of the beneficiary and describe the reason for raising funds.

Name of contributors refers to a name that can identify a contributor. Although medical crowdfunding platforms support an option for anonymous donations, contributors often write their real name to signal their contribution and to motivate others' contributions [22].

Amount of contributions is the size or frequency of contributions. In online collaborative systems such as Wikipedia and Github, the amount of contributions often signals an individual's commitment to the community $[5,6,27]$. In social media, frequent interactions signal a close relationship between the poster and the receiver [13].

Dates of contributions refer to the exact dates of each contribution. Recent contributions in an online community signal the contributors' current interest [27]. Showing recent Facebook posts on the "See Friendship" page allows the post recipient to reflect on the current state of their friendship [33]. However, displaying posts in reverse chronological order sometimes makes it difficult for the post recipient to reflect on the beginning of their friendship.

Detailed information about contributions indicates specific information about contributions such as messages and pictures associated with contributions. Although pictures associated with contributions often receive the most attention when browsing through many contributions [33], current medical crowdfunding interfaces only show contributors' messages. Individuals often infer personal relevance and contribution opportunities from detailed information about contributions such as comments associated with contributions $[5,28]$.

Types of contributions refer to different categories of contributions. On Github, types of contributions such as code and comments signal the contributor's skill sets [28]. In social media, people feel closer to the contributors who made "composed" contributions such as comments, posts, and messages rather than "one-click" contributions such as 
"likes [1]." Humorous posts especially signal a close relationship between the contributor and the receiver [40].

Link to the source of contributions indicates that contributions contain a link to the source. A link to a social media account often signals that the contribution is credible $[23,38]$.

The goal of this study is to understand 1) what contribution features medical crowdfunding beneficiaries and contributors prefer to display when recognizing contributors and contributions and 2) what inferences they make from each contribution feature. Specifically, we investigate the following research questions:

RQ2a: How do beneficiaries and contributors prefer to display contributors and contributions using the contribution features on medical crowdfunding campaigns and why?

RQ2b: How do beneficiaries and contributors perceive the contribution features displayed on medical crowdfunding campaigns?

\section{METHODOLOGY}

To answer our research questions, we conducted semistructured interviews with fourteen participants, including six beneficiaries and eight contributors to medical crowdfunding campaigns. Our beneficiary participants included two fundraisers. One (B5) raised funds for her friend and the other (B6) solicited funds for her brother who was in a coma. In this paper, we also refer to the fundraisers as beneficiaries. Of our fourteen participants, twelve were female, with an average age of 32. Their occupations varied, including, for example, graduate student, event planner, and game programmer.

We first focused our recruitment on medical crowdfunding beneficiaries. Our inclusion criteria were people who have created or benefited from an online medical crowdfunding campaign that received at least three monetary and five non-monetary contributions. We included the minimum contribution criteria to filter out people who created a medical crowdfunding campaign just to participate in our study. To ensure our participants met these criteria, we asked participants to provide a link to their campaign webpage. To recruit medical crowdfunding beneficiaries, we sent emails to local communities and posted flyers in various public places. Although we also attempted to contact potential participants via popular medical crowdfunding sites (GoFundMe, YouCaring, and Fundly) by sending direct messages on the sites, the sites did not allow us to recruit there. We were able to recruit six beneficiaries in total.

To recruit contributors, we used a snowball sampling method, asking our beneficiary participants to contact their contributors. We recruited the contributors of our beneficiary participants to investigate whether contributors accurately perceive the information conveyed by

\begin{tabular}{c|c|c} 
Campaign Type & Beneficiary & Contributor \\
\hline Dental \& Eye surgery & B1 & C1, C2, C3 \\
\hline Drug Overdose & B2 & C4, C5 \\
\hline Breast \& Brain Cancer & B3 & \\
\hline Heart Disease & B4 & \\
\hline Ovarian Cancer & B5 & \\
\hline Stroke \& Heart Attack & B6 & \\
\hline Skin Cancer & & C6, C7, C8
\end{tabular}

Table 1. Summary of study participants

beneficiaries. Our beneficiary participants either distributed our study information on their social media pages or contacted their contributors directly. Despite our beneficiary participants' effort, only five contributors signed up for our study. To recruit more contributors, we posted flyers to various public places, and recruited three more contributors. Table 1 shows the relationship between beneficiary and contributor participants. For example, C1 contributed to B1's campaign and the beneficiary of $\mathrm{C} 6$, C7, and C8 did not participate in our study.

\section{Study Procedure}

The interviews consisted of two sessions: a self-reflection session and an interface design session. 14 participants were interviewed via Skype and Google Hangouts. One local participant came to our lab for the interview. The interviews with beneficiaries lasted approximately ninety minutes; the duration of the contributor interviews was approximately fifty-five minutes. A $\$ 30$ or $\$ 20$ gift card was offered to each beneficiary and contributor participant, respectively. We compensated beneficiaries more than contributors because it was more challenging to recruit them and because of the sensitive nature of the medical and financial information they were sharing.

The Self-Reflection Session

During the self-reflection session, we showed participants their medical crowdfunding campaign webpages to remind them about the information presented in the campaign. For remote participants, we asked them to share a screen that displayed their medical crowdfunding campaign page. Remote screen sharing features in both Skype and Hangouts allowed us to view the same webpage with participants.

With our beneficiary participants, we explored their existing methods of presenting information on their medical crowdfunding campaign. We first asked about the most important impression that they wanted to convey about themselves. We then asked how they tried to signal this impression on their medical crowdfunding campaign. We further asked about the challenges they encountered in conveying this desired impression.

With contributor participants, we investigated how they perceived the information displayed on their beneficiary's medical crowdfunding campaign. We first asked them to 
name interface features or information that motivated them to contribute to the campaign. Then, we asked about inferences they made from the information presented on a campaign and how the inferences influenced their contributions.

\section{The Interface Design Session}

We provided beneficiary and contributor participants with a new webpage that allowed them to customize a medical crowdfunding campaign by modifying the contribution features introduced in the previous section (Figure 2). The contribution features included contributor names, contribution amounts as a monetary value, links to the contribution sources (e.g., source site such as Facebook), contribution dates, contribution details (messages and images), and contribution types (e.g., financial donation, social media sharing, and offline contributions). The contribution types can also be displayed in the form of an icon. We additionally included the icon feature to increase the legibility of the contribution types. Using the specifications menu bar shown on the left side of the webpage (Figure 2-1), participants can toggle each feature on the customizable interface (Figure 2-2). The design of the interface (Figure 2-2) resembled a contribution interface on an existing medical crowdfunding campaign (Figure 13). By toggling the features, participants could experience what the interface would look like with the additional features. Unlike the existing contribution interface, our customizable interface displayed both monetary and nonmonetary contributions. Through the interface design session, we aimed to understand 1) what kind of contribution features both beneficiaries and contributors preferred to display and 2) what inferences they made from their chosen contribution features, and 3) the potential impact of presenting non-monetary contributions on medical crowdfunding interfaces.

We collected participants' contribution data before each interview so we could display it on the customizable interface. Collecting non-monetary contributions required additional effort because they were not publicly visible on crowdfunding campaigns. Non-monetary contributions consist of campaign promotions and offline contributions [22]. To gather campaign promotion data, we searched for and collected posts containing the beneficiary's campaign URL on various social media sites such as Facebook, Twitter, and Instagram. We also did a Google search for the campaign URL to collect publicly available news articles and online community promotions about the beneficiary's medical crowdfunding campaign. In addition, we asked beneficiaries to add any types of contributions that occurred offline themselves. Examples of manually added contributions included renting a car, babysitting, renting an apartment, and housecleaning.

During the design session, we asked beneficiary participants to design their own interface using the customizable interface (Figure 2). We then asked

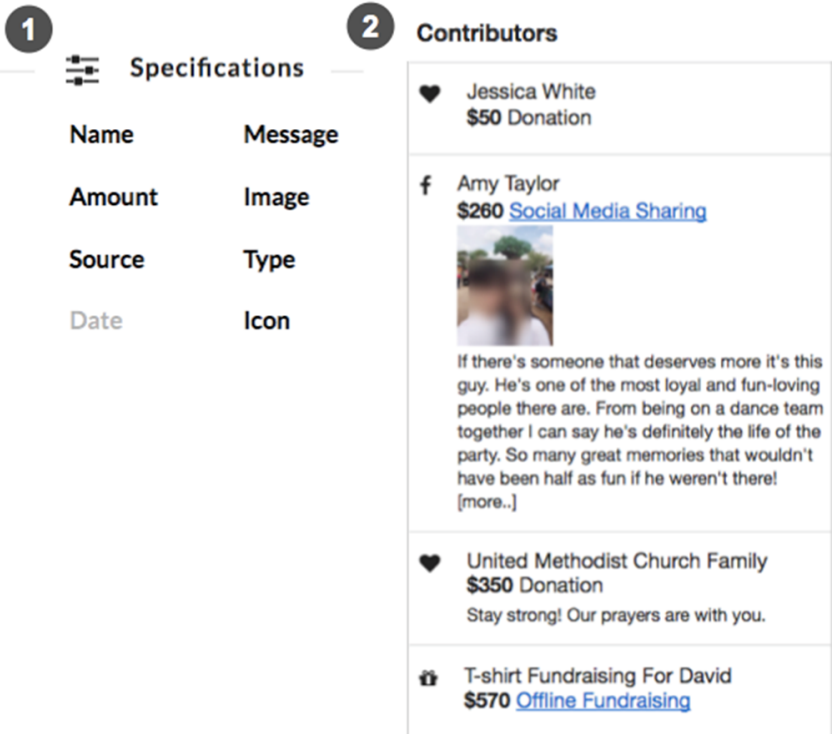

Figure 2. A webpage for customizing a medical crowdfunding interface by modifying contribution features: Using the specifications menu bar (1), users can toggle each contribution feature that appears on the customizable interface (2).

beneficiary participants why they chose to show and hide each feature. And conversely, to investigate how contributor participants perceive the contribution features displayed on the beneficiary's interface, we also asked contributor participants to design the beneficiary's interface. We then asked contributor participants what inferences they made from each feature displayed on the interface.

\section{Data Analysis}

All interviews were recorded and transcribed. To analyze the transcribed data, we used Nvivo [41] and conducted inductive coding [36].

To answer RQ1, we began by coding the information that our beneficiary participants highlighted in their medical crowdfunding campaign, their reason for emphasizing the information, and the way they presented the information. From the contributors' interview data, we coded the inferences that our contributor participants made from the information presented on medical crowdfunding campaigns. Two researchers grouped the information and the inferences based on common themes until they reached consensus. We repeated this analysis process for the second research question.

To answer RQ2, we identified common contribution features that both beneficiary and contributor participants preferred to display or hide on a medical crowdfunding campaign. For each contribution feature, we coded 1) the inferences that participants made and 2) the reason that participants desired to display or hide them. We then categorized the interface features based on common inferences and the reasons behind them. In the next session, we present our final grouped categories. 


\section{RESULTS (RQ1): SELF-PRESENTATION}

In this section, we describe how beneficiary participants desired to present their strong identity using pictures of their positive moments. At the same time, beneficiary participants felt obligated to present their sick identity that they believed their contributors want to see (RQ1a). In contrast to the beneficiaries' expectations, our contributor participants perceived positive pictures as more impactful than pictures depicting dire conditions because the positive images helped them infer the beneficiary's character and common connections to the beneficiary (RQ1b).

\section{Pictures of Beneficiaries: Capturing Positive Moments vs. Presenting Dire Conditions}

Beneficiary participants chose happy and good-looking pictures of themselves to break stereotypes associated with their medical conditions. For example, B2, who raised money for her brother who died of a drug overdose, selected a profile picture of her brother with a neat and tidy appearance. She did not want people to consider him "a street person." The other beneficiary participant, who experienced human trafficking, chose a smiling picture of herself because she did not want to be seen as a victim, but rather as a brave survivor of abuse. Beneficiary participants did not want to be seen as the pitiful or needy person often depicted in charity solicitation letters. Instead, they wanted to be presented as a person like everyone else and who can overcome their difficulties with the help of others: "I wanted people to see that he [my brother] is just like everybody else. When you think of someone who dies of an overdose, [...] we try to imagine the person as someone as far away from us, [...] nothing like our brother or sister. They're like a street person or in alleys or dirty. You know he was not. He was handsome and clean and took pride in his appearance. So I wanted to show people that you don't have to look a certain way." - B2

Beneficiary participants conveyed authenticity and seriousness through pictures depicting the beneficiary's medical conditions (e.g., pictures taken in the hospital bed or tumor pictures). Although all of our beneficiary participants believed in the importance of sharing medical condition pictures, some of them faced challenges. For example, B1 could not post these pictures because her conditions (losing her eyesight and having a dental issue) were invisible. She also could not share her medical paperwork because she did not see her doctor before she created her campaign. Similarly, B5 who was raising funds for her friend decided not to share pictures illustrating her friend's suffering since she would pass away soon: "If you know they [beneficiaries] were getting better, I feel more comfortable with that [sharing pictures of her ill]. But because we knew what Melinda's inevitable end was, I felt this is the way people would want to remember [her]." Despite the challenges the beneficiary participants faced

\footnotetext{
${ }^{1}$ We changed all the names of people in the text of this paper to protect their privacy.
}

sharing pictures of their dire medical conditions, some of them still felt guilty about not sharing such pictures. They worried that contributors might perceive that their need is not great enough to deserve financial contributions: "People don't know this [dyed] hair thing is all free because it usually takes $\$ 600$ with my length of hair. They don't know this is the present from other people. That little bit makes me feel insecure. I feel already guilty about [asking for money]." - BI

While beneficiary participants often felt obligated to present their medical conditions in a serious manner, contributor participants gave less attention to the pictures illustrating dire medical conditions. Rather, they focused on the beneficiary's character. Contributor participants inferred a bright and positive personality from pictures of a smiling beneficiary. Pictures taken with friends and family, especially in volunteering activities, conveyed the beneficiary's social and giving characteristics. The contradiction between a picture capturing the beneficiary's "silver lining" moment and a fundraising description depicting dire medical situations provoked contributors' emotional responses. Because some of the contributor participants could relate to beneficiaries when they were looking at the pictures from the beneficiary's normal life, they felt more empathy when they read the beneficiary's medical story: "When you emphasize the depth of the situation and the neediness, that definitely makes it real. But, it doesn't necessarily make someone want to contribute. To be honest, there are many people in needy situations. But if you don't have a personal connection to [them], you're kind of trained to just look past it. I think it's important to emphasize how good his character is because it makes him seem more deserving." - C7

\section{Detailed Medical and Financial Situations in a Campaign Description}

Beneficiary participants wanted to signal their honesty and courage by describing their financial and medical situations in detail in the campaign description. Because they were asking for financial contributions for their personal medical situations, half of the beneficiary participants worried that audiences might perceive them as "lazy", "cheating", or as "taking advantage of people". It took courage to share their sensitive and traumatic experiences, such as how a participant lost her sight because of severe abuse and how much a family was unprepared to lose a brother from a drug overdose. Although some of the beneficiaries' family members were opposed to sharing details, beneficiary participants felt that to be deserving of a contribution they must share: "You kind of don't overcome that concern [being guilty about asking for money]. It still exists. The only thing you can [do to] compensate that is to be honest and let people know everything that's happening. [Then,] maybe people who thought I was cheating in the beginning will read more updates, details, and pictures." - BI 
Beneficiary participants expressed their gratitude to contributors by updating their medical progress on their campaign pages. Most of our beneficiary participants had approximately 7 to 12 updates (at most 108 updates). They updated their detailed medical journey, which included information about how hard they searched for the cheapest surgery, their pre- and post-surgery progress, and up-to-date reports on their medical expenditures. From the steady updates, contributor participants inferred the beneficiary's diligence and gratitude to contributors: "It's really great to feel invested and connected by getting those updates and see how she's able to get things done and I was able to help facilitate that with my donation." - C2

\section{RESULTS (RQ2): CONTRIBUTORS \& CONTRIBUTIONS}

In this section, we describe how our beneficiary and contributor participants preferred to highlight all the contribution features on their campaign webpage except for the contribution amount (RQ2a). The reasons given for displaying contribution features were that they: 1) assisted contributor participants infer the beneficiary's character, common connections, and sincere community support around the beneficiary and 2) helped beneficiary participants view themselves as beloved members of a community by telling stories about how each contributor evolved in their medical journey (RQ2b; see Table 2). This storytelling is done by discovering: where the beneficiary's contributors come from (contributor names), why the contributors support the beneficiary (contribution details), where in the beneficiary's medical journey each contributor belongs (contribution dates), and how much the beneficiary matters to each contributor (contribution types and sources).

\begin{tabular}{l|l|l}
$\begin{array}{l}\text { Contribution } \\
\text { Features }\end{array}$ & \multicolumn{2}{|c}{ Inferences } \\
\cline { 2 - 3 } $\begin{array}{l}\text { Contributor } \\
\text { names }\end{array}$ & $\begin{array}{l}\text { Past and current } \\
\text { relationships }\end{array}$ & $\begin{array}{l}\text { Common } \\
\text { connections }\end{array}$ \\
\hline $\begin{array}{l}\text { Contribution } \\
\text { details }\end{array}$ & $\begin{array}{l}\text { Memories with } \\
\text { contributors }\end{array}$ & $\begin{array}{l}\text { Beneficiary's } \\
\text { character }\end{array}$ \\
\hline $\begin{array}{l}\text { Contribution } \\
\text { dates }\end{array}$ & Medical journey & $\begin{array}{l}\text { Activeness of the } \\
\text { campaign }\end{array}$ \\
\hline $\begin{array}{l}\text { Contribution } \\
\text { types }\end{array}$ & Sincere community support \\
\hline $\begin{array}{l}\text { Contribution } \\
\text { sources }\end{array}$ & $\begin{array}{l}\text { Opportunities for interacting with other } \\
\text { contributors }\end{array}$ \\
\hline $\begin{array}{l}\text { Contribution } \\
\text { amounts }\end{array}$ & $\begin{array}{l}\text { Characteristics about contributors (e.g., } \\
\text { stingy or generous personality) }\end{array}$
\end{tabular}

Table 2. Contribution features and inferences perceived by beneficiary and contributor participants

\section{Contributor Names Signaling Common Connections}

Contributor names allowed beneficiary participants to tell stories about how various people from different parts of the beneficiary's life came together to support the beneficiary. For example, beneficiary participants felt very supported when they saw the names of their close friends, old friends, distant friends, and even strangers with a similar medical situation in one place. Beneficiary participants displayed contributor names so that other mutual friends could recognize their friend's names and feel as if there were a community: "I know Kevin, and I know Mary and they know each other. Even though Kevin lives in Georgia and Mary lives in California. They are able to see that they are both partnering with us. Because they knew each other back in college and now we are in [a] totally different situation, they are still part of the story." $-B 4$

As beneficiary participants expected, contributor participants looked for the names of their friends on the contribution interface. Contributor participants, even people who were not close to the beneficiary, felt more connected to the beneficiary when they saw the names of mutual friends. Contributor participants also discovered common connections between the beneficiary and organization contributors (e.g., a church). For example, the name of a dance club, a church, or a fraternity signaled the beneficiary's hobbies or religion that contributors often did not know about.

\section{Contribution Details (Messages and Pictures) Conveying the Beneficiaries' Characters}

Beneficiary participants preferred to emphasize the contributors' messages because they evoked fond memories. Especially relevant were the messages posted on contributors' social media pages because they often contained very detailed shared experiences between the beneficiary and contributors. For example, a contributor described how often she cried on the beneficiary's shoulder when she was going through a rough time. Other contributors also mentioned the beneficiary's personal characteristics such as "He's one of the most loyal and funloving people." Beneficiary participants thought such messages would do a better job of showcasing their character. For example, beneficiary participants felt that descriptions of the beneficiary written by contributors were more trustworthy than those written by the beneficiaries themselves: "What other people said can be more trusted. Because there are so many things that you don't know about yourself, but other people know about you."

Contributor participants enjoyed reading messages and seeing pictures from fellow contributors. These messages and pictures represented the beneficiary's character because they showed why fellow contributors were supporting the beneficiary and promoting the campaign to their friends on social media. For example, contributors often wrote long and personal messages to explain how beneficiaries touched many different people's lives in different ways. Especially meaningful were pictures shared by contributors, which visually represented the beneficiary's character and personality remembered by contributors: "It [images from contributors] just shows that he's a guy who really cared about his family and friends, always smiling, [a] happy-golucky kind of person. This further solidifies everything that some of my friends said about him, being a nice guy." - C6 


\section{Contribution Types, Sources, and Dates Signaling Medical Story}

Beneficiary participants preferred to display various types of contributions with the exact dates of contributions. They wanted to show that different types of contributions were equally valuable and precious in every step of their medical journey. For example, by seeing many donations, social media shares, and offline contributions received in one particular day, beneficiary participants could tell a story about how these contributions supported them when they had surgery or when a beneficiary's son passed away: "Seeing the contributions and sharing that has been made to keep us going. It's been a comfort. It's like a blanket. These are the people who have been a part of the fabric of the thing that has held me together. " - B3

Instead of focusing on financial contributors, beneficiary participants desired to recognize how each contributor contributed to specific stages of their medical journey. They believed that this kind of contribution interface, emphasizing story, could lessen guilt for people who could not afford to donate money: "People can feel a part of a story. They may not be able to contribute very much financially, but they can still feel like they can be part of it. They can always share it [a campaign] and say, 'Here [is] how I was part of the GoFundMe page. Even though I wasn't able to give financially, here's a way I was participating.' I can see how that would take the pressure off on the financial piece." - B4

Contributor participants preferred to see the latest contributions first in the contribution interface because they could infer the level of activity of the beneficiary's campaign from the most recent contributions. We also found that contributor participants enjoyed seeing various types of contributions, as shown in Kim et al. [22]. Various types of contributions signaled the beneficiary's importance to each contributor. For example, some contributors lent their car for two months to the beneficiary; other contributors organized an online t-shirt-selling fundraiser. These creative external contributions triggered other potential contributors' participation. Further, showing the contribution sources (e.g., links to contributors' social media account) made contributor participants want to interact with other contributors by leaving comments on social media campaign shares or being friends with fellow contributors: "I immediately found like three people that supported somebody that's really important to me. I didn't know they supported it in a big way. It makes me reach out and thank them. I might want to make friends with some of these people or follow them." - Cl

\section{Contribution Amount as a Signal of Contributors' Characteristics}

Contribution amount allowed both beneficiary and contributor participants to infer aspects of contributors' personalities: generosity, stinginess, and boastfulness. Half of both beneficiary and contributor participants did not want to show contribution amounts from individual contributors because it resulted in judgments made about the contributors based on the amount they donated.

Small Amount - a Generous or Stingy Personality

Beneficiary participants often inferred the generosity of contributors from five- or ten-dollar contributions if they were aware that the contributor had a difficult financial situation. At the same time, beneficiary participants worried about these contributors; they did not want the contributors to feel embarrassed about their donation amount. On the other hand, contributor participants often believed that fellow contributors who made a small contribution had a stingy personality. Knowing other contributors' incomes or profligate spending habits sometimes made contributor participants judge other contributors: "It [contribution amount] has further relationship implications. People are taking what they see here and layering that with what they know of you in another way. [...] 'Oh, I know you spent $\$ 100$ a week on your nails and you only gave $\$ 5$ to this person." " $-C 4$

\section{Large Amount - a Generous or Boastful Personality}

Large donations often signal generosity [18]. However, some of our contributor participants interpreted a large donation amount as a form of bragging. For example, one participant judged the motivation of a contributor who donated twice as much as other fellow co-workers negatively. She said, "I think there are people that are driven by just wanting to [one-] up the other person. [...] Just knowing this person, they're one of those people that always have to one-up everybody else. They always have to go on the better vacation. They always have to mention the name brands of their belongings." Beneficiary participants further worried that some people might donate less than what they had originally planned just because their other friends donated a small amount.

\section{DISCUSSION}

Our results suggest two main factors that make selfpresentation in medical crowdfunding unique from other social media and online communities: 1) social expectations about people who seek and provide financial support and 2) the misalignment between what the beneficiary participants believe contributors want to see and what contributors prefer to see. In this section, we discuss how these two factors contribute to unique self-presentation practices performed on medical crowdfunding and how these practices suggest novel design opportunities for medical crowdfunding campaigns.

\section{Unique Self-presentation in Medical Crowdfunding}

As people who interact with others online are interested in self-presentation $[8,40]$, patients who share their health situations on social media often desire to portray themselves as positive and strong [30]. However, our beneficiary participants felt obligated to present themselves as in need. They worried that happy looking profile pictures might lead people to perceive that they are not in a desperate enough situation to deserve financial support. 
Thus, to convey the image that contributors might expect, some beneficiary participants felt obligated to describe their potentially sensitive medical situations (e.g., humantrafficking, drug overdose) in campaign descriptions, even against the objection from their family members. Despite the beneficiary participants' perceived expectation of contributors, our study suggests that contributor participants were more intrigued by the beneficiary's character and mutual connections than the detailed description of medical situations. While Kim et al. found that the detailed medical situation presented on medical crowdfunding campaigns was critical to assess the trustworthiness of beneficiaries [23], we discovered that the beneficiary's character and contributors' sense of connection with the beneficiary was more important when deciding whether to make an actionable donation.

Our contributor participants inferred the beneficiary's character, common connections, and sincere community support from contribution features. However, publicly displayed monetary contribution amounts resulted in judgmental attitudes regarding the contributors. This negative inference about contribution amount is unique to medical crowdfunding because contribution amounts in other online communities often signal the contributor's level of commitment $[5,6,27]$. In medical crowdfunding, however, publicly visible financial contribution amounts make contributors judge the amount based on their prior knowledge of those contributors (e.g., profligate spending or braggadocio personality). In the next section, we suggest designing a medical crowdfunding interface that goes beyond presenting individual contribution amounts to emphasizing positive aspects of contribution features.

\section{Design Opportunity: A Storytelling Interface}

Our results (see Table 2) suggest that the contribution features together could support storytelling about the beneficiary's standing in their community. This type of storytelling influences how a patient constructs self-identity [26]. Medical crowdfunding beneficiaries often experience an identity shift from a sick person to a more open person as they publicly write about their medical needs in a crowdfunding campaign [16]. Our work further found that beneficiaries come to view themselves as a "loved" and "well-appreciated" person when they see contributors and contributions from their community. In this section, we describe possible ways of designing a medical crowdfunding interface to better assist storytelling. We further discuss prospective benefits of the storytelling interface for both beneficiaries and contributors.

\section{Storytelling a Medical Journey}

Showing the exact date of each contribution allowed our beneficiary participants to tell a story by connecting contributions to the most recent medical incidents (e.g., surgery). However, viewers who don't remember the exact dates of medical incidents might not be able to make this association. One way to highlight this association is to connect the contribution interface with campaign updates. Beneficiaries already describe their medical journey by posting updates within the campaign. Categorizing the contributions into groups based on the dates and connecting each group to the nearest updates can further support the storytelling. Understanding how their contribution is connected to a stage of the beneficiary's medical journey may give contributors a sense of belonging to a specific campaign community and story. Furthermore, this storytelling interface might better help beneficiaries experience a shift in their identity from an ailing to a beloved member of a community.

\section{Suggesting More Personalized Messages for Sharing}

The storytelling interface can assist people in writing more specific and personal messages when promoting campaigns. Campaign promotions are critical to a crowdfunding campaign [21,22,31]. However, audiences are likely to ignore the shared messages if they are automatically generated [10]. While showing contributors' support associated with specific medical updates, the system can guide contributors to write more personal and specific messages about why and how they are supporting a beneficiary.

\section{Highlighting Common Connections}

A study on Facebook found that people who shared more information about themselves, such as hobbies and the schools they attended, had a higher number of friends as they established more "common referents" [25]. Our contributor participants were also more willing to make a contribution when they discovered common referents such as a mutual friend and a common organization. To help more medical crowdfunding contributors establish common referents, medical crowdfunding platforms can suggest that campaign creators specify the beneficiary's community attributes such as school, hobbies, and hometown in the campaign description. The platforms can further scaffold medical crowdfunding contributors to describe their relationship with the beneficiary, common organizations, or personal experiences when making their contributions. By grouping the contributors based on common referents, medical crowdfunding contributors might feel more involved in a community and learn more about the personal side of their beneficiary. Beneficiaries can also learn more about their contributors.

\footnotetext{
Non-monetary Contributions for Story Richness \& Legitimacy

Incorporating non-monetary contributions into a medical crowdfunding interface could add richness to the story and add to the legitimacy of a campaign [23,35]. For example, when one of our beneficiary participants wrote an update about a trip for her son's surgery, respondents offered to loan their cars or to find people who would rent out their residences. Beneficiary participants told richer stories with various non-monetary contributions because they could reflect how different types of contributions supported their lives together. Non-monetary contributions further signal
} 
the legitimacy of a campaign because they show how much the beneficiary is appreciated by contributors [35]. Particularly, contributors' messages that endorse the beneficiary's personality and describe the beneficiary's impact on their lives can increase the beneficiary's trustworthiness. People trust information generated by others more than self-generated information [17].

\section{Design Challenges}

There are several challenges we need to consider when incorporating previously invisible non-monetary contributions into medical crowdfunding campaigns [34,35]. First, designers should consider privacy issues that contributors might face when incorporating social media shares and offline contributions; perhaps contributors should control what to display for their contribution. However, it is also important to give beneficiaries the capability to add and remove the non-monetary contributions to resolve potential problems. For example, one of our beneficiary participants received negative comments on her medical crowdfunding campaign from her family members who were opposed to creating a campaign. Beneficiaries should be able to remove the contributions that they believe may negatively influence how they are perceived. Second, contributors should continue to have an option to display their support anonymously. Medical crowdfunding contributors sometimes prefer to hide their name, to be discreet. Thus, the system should support existing practice. Third, designers should consider ways to minimize additional work produced by including nonmonetary contributions [34]. For example, if beneficiaries spend too much time and energy managing the presentation of their non-monetary contributions, their well-being, given their health concerns, might be affected negatively. Finally, the medical crowdfunding interface incorporating nonmonetary contributions might not be effective for beneficiaries who have few non-monetary contributors. They might feel more discouraged about having fewer contributors than other beneficiaries [19]. We need to find better ways to support those beneficiaries who may lack friends or family to provide non-monetary contributions.

\section{LIMITATIONS \& FUTURE WORK}

Our study results come from a small number of beneficiary and contributor participants. Despite a wide recruitment call, few medical crowdfunding beneficiaries signed up for our study. The low response rate might be due to the beneficiaries' emotionally and physically difficult medical situations. Moreover, we faced challenges recruiting medical crowdfunding contributors of our beneficiary participants. Although we attempted to overcome this limitation by recruiting medical crowdfunding contributors without their beneficiaries, we could only recruit three additional contributor participants. Other contributors who signed up for our study could not participate because we could not find at least five non-monetary contributions in their medical crowdfunding campaign. Our inclusion criteria (medical crowdfunding campaigns with at least five non-monetary and three monetary contributions) were created because some non-monetary contributions were necessary to investigate contribution display preferences.

There are both advantages and disadvantages to interviewing contributors who know the beneficiaries. The advantages include understanding how those contributors use contribution features to signal their close relationship with the beneficiaries. However, we may have missed other possible uses of contribution features by not including contributors who do not know the beneficiary.

With the implications derived from this exploratory study, we aim to build a new contribution interface for medical crowdfunding campaigns as a next step of this study. Our goal is to evaluate the contribution interface that supports storytelling with a larger pool of beneficiaries and supporters. We hope such a large scale study could suggest new insights and validate the impact of displaying various contributions on medical crowdfunding campaigns.

\section{CONCLUSION}

In this work we first examined how medical crowdfunding beneficiaries present their identity on a campaign and how contributors perceive them. We then explored how beneficiaries and contributors prefer to present monetary and non-monetary contributions. From the interviews with both beneficiaries and contributors of medical crowdfunding campaigns, we found that beneficiary participants often felt obligated to emphasize their ailing identity to signal that they deserved financial support. However, contributor participants were more interested in signals conveying the beneficiary's character and their common connections to the beneficiary. Interestingly, the beneficiary's character and common connections were often inferred from various contribution features (e.g., contributor names, messages, shared images). These contribution features also supported beneficiary participants in telling stories about how each contributor was involved in their medical journey. Furthermore, the storytelling aspect allowed beneficiary participants to view themselves as people who are valued members of a community. However, our participants did not want to publicly display the contribution amount because the amounts sometimes made contributors judge others negatively. Thus, we suggest designing a medical crowdfunding interface that can better assist storytelling rather than focus on the donation amount. We hope this medical crowdfunding storytelling interface can help both beneficiaries and contributors be more aware of how they are involved in a supportive community throughout the process of medical crowdfunding.

\section{ACKNOWLEDGEMENTS}

We would like to thank all of our participants. This work is supported by National Science Foundation (NSF) grant: CCF-1029679 and National Research Foundation of Korea (NRF) grant: 2017R1D1A1B03033309. 


\section{REFERENCES}

1. Moira Burke and Robert Kraut. 2014. Growing Closer on Facebook: Changes in Tie Strength Through Social Network Site Use. Proc. CHI 2014. http://doi.org/10.1145/2556288.2557094

2. Gordon Burtch and Jason Chan. 2014. Reducing Medical Bankruptcy Through Crowdfunding: Evidence from GiveForward. Proc. ICIS 2014, 1-19.

3. Munmun De Choudhury and Sushovan De. 2014. Mental Health Discourse on reddit: Self-Disclosure, Social Support, and Anonymity. Proc. ICSWM 2014: 71-80.

4. Chia-fang Chung, Elena Agapie, Jessica Schroeder, Sonali Mishra, James Fogarty, and Sean A Munson. 2017. When Personal Tracking Becomes Social : Examining the Use of Instagram for Healthy Eating. In Proc. CHI 2017. http://doi.org/10.1145/3025453.3025747

5. Laura Dabbish, Colleen Stuart, Jason Tsay, and Jim Herbsleb. 2012. Social Coding in GitHub: Transparency and Collaboration in an Open Software Repository. Proc. CSCW 2012, 1277-1286. http://doi.org/10.1145/2145204.2145396

6. Katie Derthick, Patrick Tsao, Travis Kriplean, Alan Borning, Mark Zachry, and David W Mcdonald. 2011. Collaborative Sensemaking during Admin Permission Granting in Wikipedia. Proc. OCSC 2011, 100-109.

7. Sanorita Dey, Brittany Duff, and Karrie Karahalios. 2017. The Art and Science of Persuasion : Not All Crowdfunding Campaign Videos Are The Same Predictors of Crowdfunding Success. Proc. CSCW 2017. http://doi.org/10.1145/2998181.2998229

8. Joan Morris DiMicco and David R Millen. 2007. Identity Management: Multiple Presentations of Self in Facebook. Proc. Group 2007.

9. Nicole Ellison, Rebecca Heino, and Jennifer Gibbs. 2006. Managing Impressions Online : Self-Presentation Processes in the Online Dating Environment. $J$. Comput. Commun. 11: 415-441. http://doi.org/10.1111/j.1083-6101.2006.00020.x

10. Daniel A. Epstein, Bradley H. Jacobson, Elizabeth Bales, David W. McDonald, and Sean A. Munson. 2015. From "nobody cares" to "way to go!" Proc. CSCW 2015: 1622-1636. http://doi.org/10.1145/2675133.2675135

11. Andrew T Fiore, Lindsay S Taylor, G A Mendelsohn, Marti Hearst, and South Hall. 2008. Assessing Attractiveness in Online Dating Profiles. Proc. CHI 2008, 797-806. http://doi.org/10.1145/1357054.1357181

12. Elizabeth M Gerber and Julie Hui. 2013. Crowdfunding: Motivations and Deterrents for Participation. ACM Trans. Comput. Interact. 20, 6: 32. http://doi.org/10.1145/2530540

13. Eric Gilbert and Karrie Karahalios. 2009. Predicting tie strength with social media. In Proc. CHI 2009, ACM Press. http://doi.org/10.1145/1518701.1518736

14. Erving Goffman. 1959. The Presentation of Self in Everyday Life. Anchor: New York.

15. Amy Gonzales. 2017. Flexibility and Intangibles: The Crowdfunding Needs of Stigmatized Individuals. Proc. CHI 2017: 2371-2375. http://doi.org/10.1145/3025453.3025647

16. Amy L Gonzales, Elizabeth Y Kwon, Teresa Lynch, and Nicole Fritz. 2016. "Better everyone should know our business than we lose our house": Costs and benefits of medical crowdfunding for support, privacy, and identity. New Media Soc. http://doi.org/10.1177/1461444816667723

17. Lauren M Hamel and Hillary C Shulman. 2009. SelfGenerated Versus Other-Generated Statements and Impressions in Computer-Mediated Communication. Communic. Res.: 229-253.

18. William Harbaugh. 1998. The prestige motive for making charitable transfers. Am. Econ. Rev. Pap. Proc. 88, 2: 277-82.

19. Emily Harburg, Julie Hui, Mike Greenberg, and Elizabeth Gerber. 2015. Understanding the effect of Crowdfunding on entrepreneurial self-efficacy. Proc. CSCW 2015: 3-16. http://doi.org/10.1145/2675133.26751 42

20. Andrea Hartzler and Wanda Pratt. 2011. Managing the personal side of health: how patient expertise differs from the expertise of clinicians. J. Med. Internet Res. 13, 3: e62. http://doi.org/10.2196/jmir.1728

21. Julie S. Hui, Elizabeth M. Gerber, and Darren Gergle. 2014. Understanding and Leveraging Social Networks for Crowdfunding: Opportunities and Challenges. Proc. DIS 2014, ACM Press, 2083-2088. http://doi.org/10.1145/2559206.2581289

22. Jennifer G. Kim, Kristen Vaccaro, Karrie Karahalios, and Hwajung Hong. 2017. "Not by Money Alone": Social Support Opportunities in Medical Crowdfunding Campaigns. Proc. CSCW 2017. http://doi.org/10.1145/2998181.2998245

23. Jennifer G Kim, Ha Kyung Kong, Karrie Karahalios, Wai-tat Fu, and Hwajung Hong. 2016. The Power of Collective Endorsements : Credibility Factors in Medical Crowdfunding Campaigns. Proc. CHI 2016. http://doi.org/10.1145/2858036.2858289

24. Jennifer G Kim, Stephany Park, Karrie Karahalios, and Michael Twidale. 2015. Labor Saving and Labor Making of Value in Online Congratulatory Messages. Proc. SocInfo 2015.

25. Cliff Lampe, Nicole Ellison, and Charles Steinfield 
2007. A Familiar Face ( book ): Profile Elements as Signals in an Online Social Network. Proc. CHI 2007: 435-444. http://doi.org/10.1145/1240624.1240695

26. Lena Mamykina, Andrew D Miller, Elizabeth D Mynatt, and Daniel Greenblatt. 2010. Constructing Identities through Storytelling in Diabetes Management. Proc. CHI 2010, 1203-1212. http://doi.org/10.1145/1753326.1753507

27. Jennifer Marlow and Laura Dabbish. 2013. Activity Traces and Signals in Software Developer Recruitment and Hiring. Proc. CSCW 2013, 145-155. http://doi.org/10.1145/2441776.2441794

28. Jennifer Marlow, Laura Dabbish, and Jim Herbsleb. 2013. Impression Formation in Online Peer Production: Activity Traces and Personal Profiles in GitHub. Proc. CSCW 2013, 117-128. http://doi.org/10.1145/2441776.2441792

29. Ethan Mollick. 2014. The dynamics of crowdfunding: An exploratory study. J. Bus. Ventur. 29: 1-16. http://doi.org/10.1016/j.jbusvent.2013.06.005

30. Mark W Newman, Debra Lauterbach, Sean a Munson, Paul Resnick, and Margaret E Morris. 2011. 'It' s not that I don't have problems, I'm just not putting them on Facebook": Challenges and Opportunities in. Proc. CSCW 2011: 341-350. http://doi.org/10.1145/1958824.1958876

31. Vineeth Rakesh, Jaegul Choo, and Chandan Reddy. 2015. Project Recommendation Using Heterogeneous Traits in Crowdfunding. Proc. ICSWM 2015.

32. Julia Sisler. 2012. Crowdfunding for medical expenses. C. Can. Med. Assoc. J. 184, 2: 123-124. http://doi.org/10.1503/cmaj.109-4084

33. Dan Sosik, Victoria, Zhao, Xuan, Cosley. 2012. See Friendship, Sort of: How Conversation and Digital Traces Might Support Reflection on Friendships. CSCW 2012, 1145-1154. http://doi.org/10.1145/2145204.2145374

34. Susan Leigh Star and Anselm Strauss. 1999. Layers of Silence, Areanas of Voice: The Ecology of Visible and Ivisible Work. Comput. Support. Coop. Work 8, 1995: 8-30. http://doi.org/10.1023/A:1008651105359

35. Katie G Tanaka and Amy Voida. 2016. Legitimacy Work : Invisible Work in Philanthropic Crowdfunding. Proc. CHI 2016. http://doi.org/10.1145/2858036.2858110

36. David Thomas. 2006. A General Inductive Approach for Analyzing Qualitative Evaluation Data. Am. J. Eval. 27, 2: 237-246.

37. Tatiana Vlahovic, Yi-Chia Wang, Robert Kraut, and John Levine. 2014. Support matching and satisfaction in an online breast cancer support community. Proc. CHI 2014: 1625-1634. http://doi.org/10.1145/2556288.2557108

38. Darcy Warkentin, Michael Woodworth, Jeffrey T. Hancock, and Nicole Cormier. 2010. Warrants and deception in computer mediated communication. Proc. CSCW 2010, ACM Press, 9-12. http://doi.org/10.1145/1718918.1718922

39. Anbang $\mathrm{Xu}$, Xiao Yang, Huaming Rao, Wai-tat Fu, Shih-wen Huang, and Brian P Bailey. 2014. Show Me the Money! An Analysis of Project Updates during Crowdfunding Campaigns. Proc. CHI 2014, 591-600. http://doi.org/10.1145/2556288.2557045

40. Xuan Zhao, Niloufar Salehi, Sasha Naranjit, Sara Alwaalan, Stephen Voida, and Dan Cosley. 2013. The Many Faces of Facebook : Experiencing Social Media as Performance, Exhibition, and Personal Archive. Proc. CHI 2013: 1-10. http://doi.org/10.1145/2470654.2470656

41. Nvivo Tool. Retrieved from http://www.qsrinternational.com 